Revista de Economia Política, vol. 30, $n^{\circ} 1$ (117), pp. 63-72, janeiro-março/2010

\title{
Juros, câmbio e o sistema de metas de inflação no Brasil
}

FRANKLIN SERRANO*

Interest rate, exchange rate and the system of inflation target in Brazil. In the consensus view of the Brazilian system of inflation targeting, the core of inflation is due to demand shocks; the rate of interest is set to control demand; and some variation in the exchange rate happens as "collateral damage". In this note we argue that in reality core inflation comes from cost push; the interest rate affects the exchange rate; changes in the exchange rate affect costs and prices; it is the effect of interest rates on demand that is the "collateral damage" and that the long run anchor of the system is low average real wage rigidity.

Keywords: interest rate; exchange rate, inflation target.

JEL Classification: E31; E43; E11.

A maioria dos defensores e críticos do Sistema de Metas de Inflação brasileiro acredita que este é operado da forma descrita pelo modelo do "novo consenso" ou "nova síntese neoclássica" de autores como J. Taylor, Blinder e P. Romer (Romer, 2000). Neste artigo, eu gostaria de expor minha visão sobre como funciona de fato o sistema e quais são os dilemas de política econômica que surgirão se a economia brasileira for retomar uma trajetória de desenvolvimento sustentado, com taxas de crescimento elevadas, maior inclusão social e redução das desigualdades.

\section{A VISÃO CONSENSUAL}

A visão consensual do regime de metas de inflação pode ser sintetizada em três proposições: a) o núcleo ou tendência da inflação é resultado de choques de de-

\footnotetext{
* Instituto de Economia, Universidade Federal do Rio de Janeiro. E-mail: franklinserrano@gmail.com. O autor agradece (sem responsabilizar) a Ricardo Summa e Alexandre Freitas, do IE-UFRJ, e a Julia Braga (UFF) por inúmeras discussões sobre o tema. Submetido: Maio 2008; Aprovado: Novembro 2008.
} 
manda; b) a taxa de juros é operada com o objetivo de controlar a demanda agregada; c) alguma variação na taxa de câmbio ocorre como um efeito colateral das mudanças na taxa de juros.

Apesar de sua ampla aceitação, estas três proposições básicas, a rigor, só se sustentam se quatro pressupostos fundamentais do modelo teórico do "novo consenso" forem válidos. Estes pressupostos são: 1 ) que o hiato do produto (e/ou do emprego) afeta a inflação de forma sistemática; 2) que os choques inflacionários têm persistência total, isto é, os coeficientes de inércia e de expectativas inflacionárias, somados, se igualam à unidade; 3) que o produto potencial é independente da evolução da demanda; 4) que os choques de custo são aleatórios, causados, por exemplo, por safras agrícolas abundantes ou excepcionalmente fracas.

Somente se estes quatro pressupostos forem válidos a visão consensual faz sentido. Os pressupostos 2) e 3) implicam que o Banco Central deve se preocupar exclusivamente com a meta de inflação, pois a política monetária é neutra e a longo prazo não afeta nem o produto nem a capacidade produtiva da economia. Os demais pressupostos garantem a possibilidade de atingir a meta da inflação controlando a evolução da demanda agregada (pressuposto 1) e que não se pode (nem se deve) fazer muito para alterar a inflação de custos (pressuposto 4). O pequeno problema é que, no caso da economia brasileira no período de 1999 até os dias atuais, nenhum destes quatro pressupostos se sustenta.

Em primeiro lugar, não se observa uma relação empírica sistemática entre o hiato do produto e a aceleração da inflação - a rigor, nem com o nível da inflação. As estimativas de diversos estudos econométricos mostram a não significância do hiato do produto na chamada Curva de Phillips (ver, por exemplo, Ferreira \& Jayme Júnior, 2005). Com efeito, uma recente estimativa do próprio Banco Central (2008, p. 133) aponta um coeficiente positivo para o período de 1996 a 2006, indicando que um aumento do desemprego aceleraria a inflação (ver também Vernengo, 2008). Mesmo considerando-se apenas o núcleo da inflação dos preços livres do IPCA, não existe relação definida entre a aceleração da inflação e o grau de utilização da capacidade produtiva da indústria (Freitas, 2006).

Em segundo lugar, no caso da economia brasileira recente, os choques inflacionários não têm persistência total sobre a inflação. Estimativas para a persistência inflacionária no Brasil mostram que esta não pode ser considerada completa, isto é, a soma dos coeficientes da inflação passada (inércia) e futura (expectativas inflacionárias) na Curva de Phillips é inferior à unidade. Existe uma persistência na inflação, mas esta é apenas parcial - em torno de 0,7 no máximo (Summa, 2007a; Maia \& Cribari-Neto, 2006). Tais fatos não podem ser refutados através do argumento das "expectativas racionais" dos agentes do mercado, pois há forte evidência de que os dados sobre a inflação esperada pelo mercado também apresentam correlação (cerca de 0,4$)$ com a inflação passada efetivamente ocorrida, indícios de existência, em algum grau, de expectativas adaptativas.

A terceira hipótese descrita acima, de que o produto potencial é independente do produto corrente, é totalmente refutada pela literatura moderna de séries temporais (Braga, 2006), tanto no Brasil quanto nos demais países. As evidências de 
existência estatística de uma raiz unitária (e, portanto, de uma tendência estocástica) no PIB mostram que a tendência do produto é totalmente correlacionada com a evolução do produto corrente (a chamada histerese para o produto). Isto parece confirmar que o investimento que cria capacidade para o setor privado é basicamente induzido pela evolução da demanda final de consumo, investimento residencial, exportações e gastos do governo, o que é compatível com o modelo do supermultiplicador (Serrano, 2007), que combina o efeito multiplicador no consumo e acelerador flexível no investimento. Um estudo recente de Barbosa-Filho (2008) mostra a forte correlação também entre o grau de utilização da capacidade produtiva e o desvio da produção industrial em relação à sua média móvel de 12 meses, evidenciando o efeito histerese no produto, que significa que qualquer crescimento mais persistente na demanda acaba estimulando aumentos do investimento e da capacidade produtiva.

Finalmente, o quarto dos pressupostos da interpretação consensual do sistema de metas, a ideia de que os choques de oferta são aleatórios, definitivamente não se aplica ao Brasil, por diversas razões. Em primeiro lugar, temos os preços monitorados, que crescem bem acima dos demais preços livres de 1999 a 2006. A maior parte dos preços monitorados são atrelados contratualmente ao IGP-M que, em geral, cresceu bem mais do que o IPCA, o que provavelmente implicou numa tendência ao aumento das margens de lucro das empresas destes setores ao longo do período como um todo. Além disso, os preços internacionais do petróleo crescem desde 1999 e os das demais commodities desde 2002, impondo crescimento semelhante aos preços dos bens importados (e pressionando para cima os preços no mercado interno dos bens exportáveis), como se vê no Gráfico II abaixo. Finalmente, o salário mínimo nominal também tem evoluído continuamente bem acima do IPCA devido à política do governo de recomposição do seu poder de compra, que está retornando aos níveis dos anos 1960.

\section{JUROS, CÂMBIO E INFLAÇÃO}

Como nenhum dos quatro pressupostos se sustenta, é evidente que o sistema de metas no Brasil não pode funcionar da maneira em que é descrito consensualmente. Ainda assim, bem ou mal, o sistema funciona: a inflação crônica não retornou a partir de 1999 e ficou contida dentro da faixa estipulada pelas metas em 1999, 2000, 2005, 2006 e 2007 (ficando acima da meta em 2001, 2002, 2003 e 2004). Então fica a questão: como é possível controlar a inflação a partir da taxa de juros, numa economia em que não há evidência de que o controle da demanda agregada seja capaz de conter diretamente o aumento de preços ou salários nominais, e onde há um conjunto de pressões inflacionárias pelo lado dos custos?

A resposta é que, na prática, o sistema funciona da seguinte maneira: aumentos da taxa de juros valorizam a taxa de câmbio nominal; as mudanças na taxa de câmbio, por sua vez, com alguma defasagem, têm um forte impacto de custos, diretos e indiretos, sobre todos os preços da economia, inclusive os "livres". 
Desde meados de 1999 até agora, apesar da enorme mudança nas condições de comércio, liquidez e taxas de juros da economia mundial, da grande virada da conta corrente brasileira, da mudança de governo e dos movimentos especulativos habituais, se observa, ainda assim, uma forte relação entre o diferencial de juros interno e externo (corrigido pelo risco país) e o nível da taxa de câmbio nominal (Gráfico I). ${ }^{1}$

\section{Gráfico I}

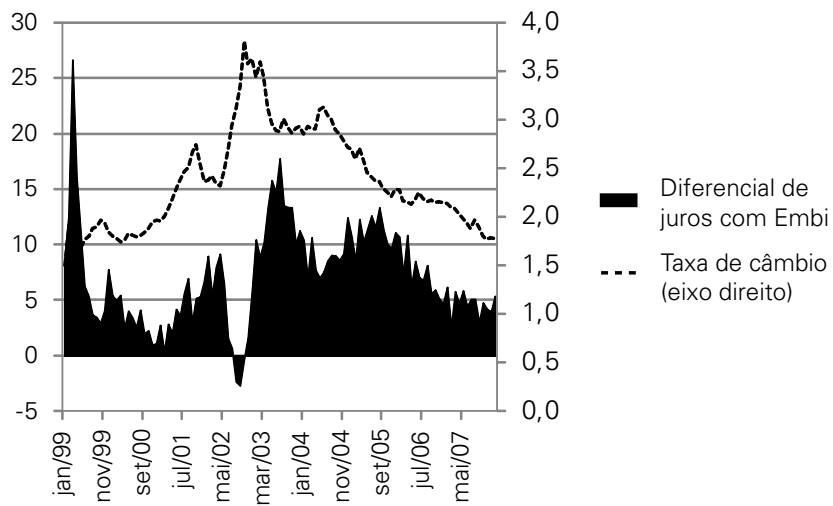

É a valorização do câmbio resultante do elevado diferencial de juros que torna possível a transformação de grandes choques de oferta negativos em dólares em choques de oferta positivos em positivos em reais, quando comparamos as taxas de variação anualizadas dos preços das importações em doláres e em reais (Gráfico II). Outro fator de controle da inflação de custos tem sido a política do governo de não repassar integralmente para os preços internos da gasolina e, especialmente, do óleo diesel, as brutais variações externas do preço do petróleo (o que ficou claro quando recentemente o governo reduziu impostos indiretos para compensar o reajuste parcial do preço interno). Veja o gráfico na página seguinte.

A maioria dos analistas acredita, seguindo a caracterização consensual descrita acima, que o efeito dos juros altos sobre a demanda agregada é o que impede que os choques de custo se transformem em aumentos da taxa de inflação. No entanto, o fato de que se não observa relação sistemática entre o hiato do produto (ou emprego) e a inflação mostra que não é isso o que ocorre. ${ }^{2}$ A política de juros

\footnotetext{
${ }^{1}$ Ver Freitas (2006). A partir de meados de 1999 (coincidentemente com o início do sistema de metas) não apenas existe uma forte relação, mas também, claramente, os movimentos da taxa de juro precedem os movimentos da taxa de câmbio nominal (ver teste de "causalidade" em Summa, 2007b).

${ }^{2}$ Uma questão interessante a ser estudada é entender por que não há efeito sistemático da demanda sobre a inflação no Brasil. É possível que em parte isso se deva ao fato de que a economia brasileira atualmente bastante aberta, o que tornaria os preços de muitos bens transacionáveis, inclusive os de commodities, que são em princípio flexíveis, insensíveis a mudanças na demanda doméstica por estes bens. Por outro lado, além dos preços monitorados que são administrados, mesmo no curto prazo, os
} 


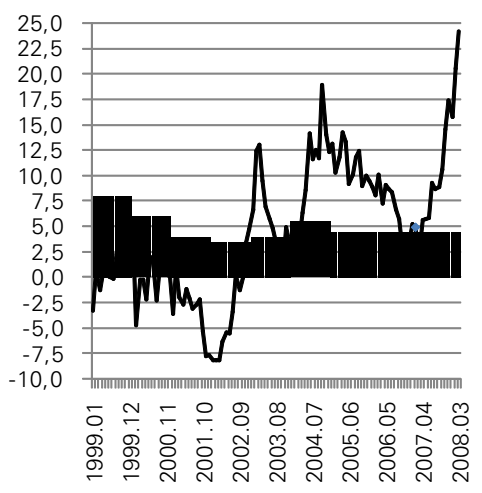

- Centro da Meta

_ Preço Importações em Dólares (var. a.a.9\%)

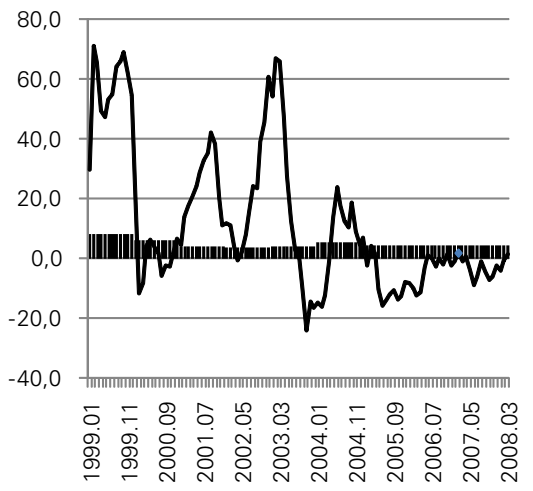

Centro da Meta

— Preço Importações em Reais (var. a.a.9\%)

elevados, ao valorizar a taxa nominal de câmbio, gera diretamente um choque positivo de custos em moeda local. ${ }^{3}$ Assim, dada a ausência do canal de transmissão tradicional da demanda para a inflação e a força do canal de transmissão dos juros para o câmbio e do câmbio para os preços, o efeito dos juros sobre a demanda agregada, na realidade, se torna apenas um efeito colateral da política monetária.

Note que, mesmo quando a economia sofreu choques cambiais adversos, advindos de problemas nas contas externas, como em 2002, o papel principal dos juros elevados não foi propriamente conter a demanda para evitar o repasse aos preços da desvalorização inicial, mas sim parar e depois reverter a desvalorização cambial nominal. Não é por outro motivo que, como nos lembra Barbosa-Filho (2007), em todos os anos que a inflação ficou dentro da faixa estipulada como meta (fora o ano de 1999 que marca a transição para o sistema) o câmbio nominal se valorizou. ${ }^{4}$ Nos anos mais recentes, o grande diferencial de juros e a con-

preços de muitos bens não transacionáveis são determinados com base em seus custos. Além disso, também não se observa flexibilidade nos salários nominais. Tudo isso restringe a possibilidade de algum efeito da demanda sobre a inflação à fração dos setores não transacionáveis que forem altamente competitivos, como o de alguns tipos de serviços pessoais, por exemplo. Outra possibilidade seria a de que muitos preços só se tornem realmente flexíveis a níveis muito elevados de pressão de demanda e certamente não ocorreram episódios deste tipo no Brasil de 1999 para cá.

${ }^{3}$ Note que como o câmbio afeta muito os preços por atacado e estes o índice que reajusta os preços monitorados a ideia muito difundida entre defensores e críticos do sistema de que os preços monitorados, por serem independentes da demanda não são afetados pela taxa de juros é totalmente incorreta, pois os juros afetam diretamente a taxa de câmbio.

${ }^{4}$ No caso de 1999 o sistema funcionou por poucos meses e a faixa da meta foi ajustada para cima. Note que em 2003 o câmbio nominal também se valorizou, mas havia se desvalorizado tanto em 2002 que, mesmo assim, a meta não foi atingida, por conta das defasagens entre câmbio e inflação. 
tínua valorização nominal do real manteve a inflação dentro da meta, apesar do forte crescimento dos preços internacionais das commodities e do petróleo em dólares.

A outra característica fundamental do sistema é que, embora o núcleo da inflação brasileira recente seja de custos, não tem havido inflação puxada pelos salários nominais médios (a despeito do grande crescimento nominal do salário mínimo). Em geral, os custos unitários do trabalho em termos nominais só têm crescido menos e depois do aumento da inflação, independentemente do nível de atividade da economia. No fundo, é a ausência de indexação salarial e a baixa resistência salarial real que explicam tanto a pouca persistência dos choques inflacionários quanto o fato da inflação crônica não retornar, mesmo quando ocorreram grandes desvalorizações cambiais. O Gráfico III mostra como as variações nominais da taxa de câmbio levam diretamente a variações reais nos salários, ilustrando a aparente ausência de resistência do salário real médio e o Gráfico IV ilustra como o crescimento dos custos salariais unitários na indústria seguem a inflação com uma defasagem.

Temos então que operação concreta do sistema de metas inflacionárias no Brasil tem as seguintes características: i) o núcleo da inflação é de custos; ii) as variações na taxa de juros afetam a taxa de câmbio; iii) as variações no câmbio afetam os custos e posteriormente os preços de todos os setores da economia. $\mathrm{O}$ primeiro impacto se dá nos preços dos transacionáveis e dos monitorados (estes via indexação ao IGP-M) e, posteriormente, o impacto dos preços por atacado afeta os custos e os índices de preços "livres" e dos não transacionáveis; iv) o efeito dos juros na demanda agregada é, afinal, apenas um efeito colateral da política monetária e v) a âncora do sistema é a baixa resistência dos salários reais médios.

Gráfico III

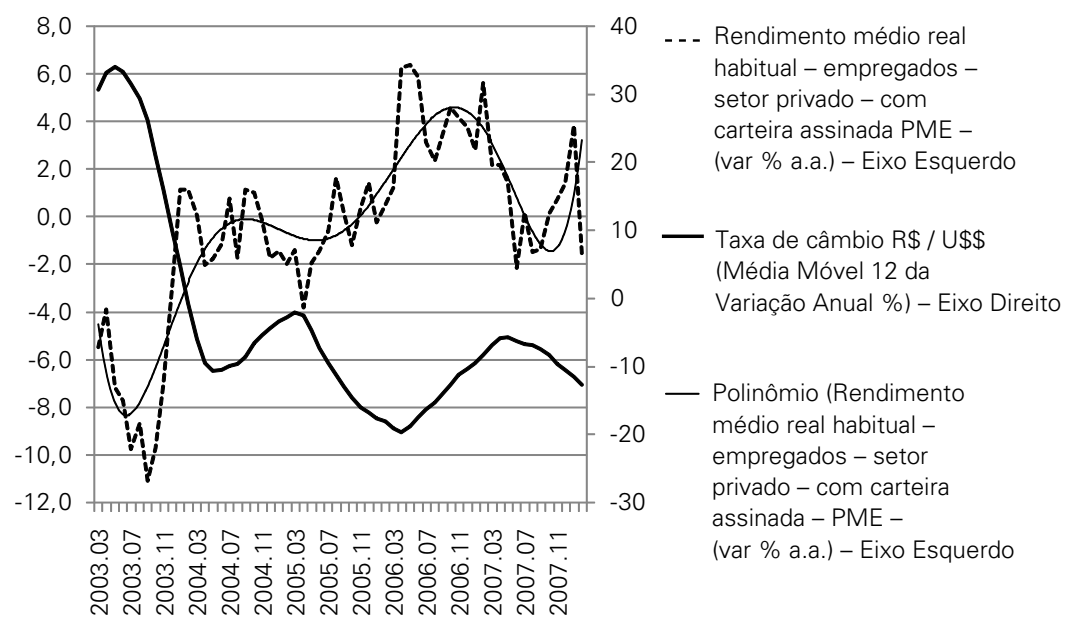




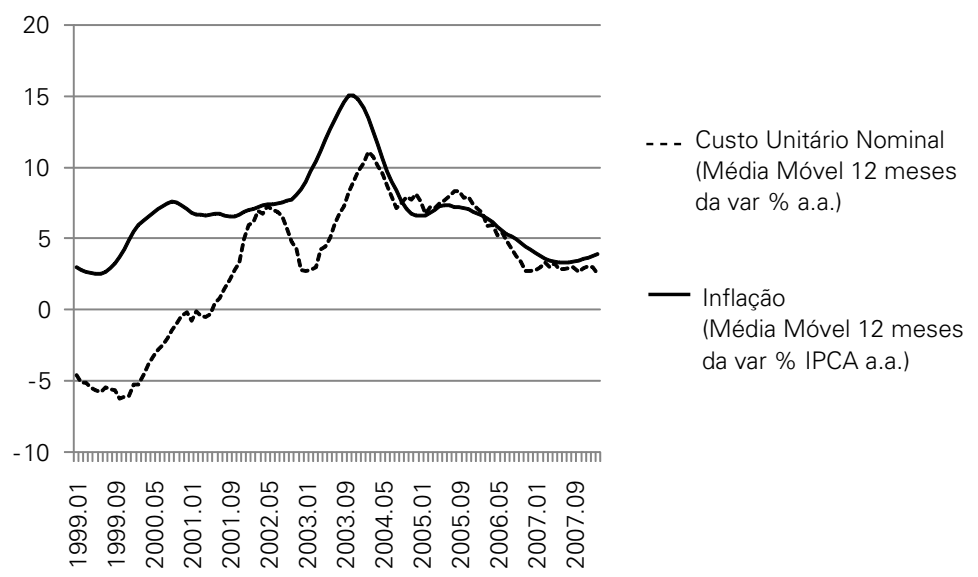

\section{PROBLEMAS, DILEMAS E ALTERNATIVAS}

Somente a partir desta caracterização mais realista de como o sistema funciona podemos discutir adequadamente os dilemas que a política econômica impõe ao desenvolvimento econômico.

É claro que o regime atual de "juros altos e câmbio baixo" tem grandes custos. Em termos fiscais, aumenta a carga de juros da dívida pública. Em termos distributivos, os juros reais elevados estabelecem um alto custo de oportunidade para o capital, o que eleva o piso aceitável das margens de lucros das empresas e concentra a distribuição funcional da renda. Os juros reais elevados atrapalham o crescimento do crédito para o consumo e para a construção civil e, a partir daí, desestimulam o investimento produtivo induzido e o crescimento do próprio produto potencial. O câmbio real cada vez mais valorizado desprotege a indústria local contra as importações, diminuindo sua competitividade, e atrapalha as exportações de produtos industriais mais sofisticados, solidificando uma inserção externa de pouco dinamismo tecnológico, baseada apenas em nossas vantagens absolutas em alguns recursos naturais.

Além disso, a tentativa de acelerar o crescimento mantendo em operação o sistema "juros altos, câmbio baixo" leva a uma explosão das importações que cria uma tendência de deterioração progressiva das contas externas, gerando déficits em conta corrente que podem, no futuro, significar o retorno da restrição externa ao crescimento.

Por vários destes motivos, é crescente o número de críticos do regime que propõem a transição para um regime de política econômica de "juros baixos e câmbio alto". O problema é que, uma vez que nos demos conta de como o sistema de metas funciona realmente, se o diferencial de juros for reduzido e o câmbio desvalorizado substancialmente, surgem algumas questões complicadas. 
Em primeiro lugar, como manter a inflação sob controle? As taxas de crescimento dos preços internacionais das commodities e do petróleo recentemente têm sido bem mais elevadas do que a meta de inflação brasileira. Se não for usado o instrumento da valorização cambial, o que se deve fazer?

Alguns economistas têm sugerido que o Banco Central use controles de crédito de diversos tipos para controlar a demanda agregada, sem ter que elevar a taxa básica de juros (evitando assim a valorização do câmbio). Outros têm sugerido a ampliação adicional dos já elevados superávits primários fiscais, que diminuiriam o crescimento da demanda agregada sem a necessidade de aumentar os juros (novamente evitando a valorização do câmbio).

O problema é que estes críticos não levam em conta que a economia está sofrendo um choque de oferta externo e não um choque de demanda interno. A economia não está superaquecida. Além disso, e mais importante, como vimos acima, não há evidência de que as flutuações no hiato do produto (ou emprego) no Brasil afetem a inflação. Estas medidas só teriam o efeito colateral de reduzir o crescimento, viés já existente na política de juros altos, e não afetariam a taxa de inflação, exatamente por não valorizar o câmbio.

Por outro lado, se houver uma desvalorização cambial e a inflação só aumentar pouco e temporariamente, como ficam os salários reais? É importante notar que, devido à indexação dos preços monitorados ao IGP-M, que é muito afetado pela taxa de câmbio, os salários reais médios serão fortemente reduzidos por uma desvalorização cambial. Curiosamente, não tenho visto nenhuma preocupação com este assunto no debate recente.

Neste caso, talvez esteja na hora de começar a se pensar em combinar desvalorização cambial com desindexação dos preços monitorados, além de taxação das exportações de alguns bens básicos, o que reduziria o custo para os salários e geraria melhora da competitividade, nas linhas do que foi feito pelo governo da $\mathrm{Ar}-$ gentina. ${ }^{5}$

Outro possível problema com a estratégia alternativa de "juro baixo e câmbio alto" diz respeito às contas externas. Diante da grande liberdade de movimento de curto prazo do capital externo, como estabilizar o câmbio e fechar a balança de pagamentos sem usar o diferencial de juros para atrair capitais? Existe aqui uma forte assimetria.

De fato, se o câmbio for muito desvalorizado e houver equilíbrio ou superávit em conta corrente, mesmo com um diferencial de juros baixo ou nulo, a tendência do mercado, a princípio, vai ser especular na direção de valorizar o câmbio, o que

\footnotetext{
${ }^{5}$ Bresser-Pereira (2008) propôs combinar a desvalorização com a taxação de produtos exportáveis tradicionais (e não as exportações tradicionais) para aumentar a rentabilidade relativa das exportações industriais modernas. Na Argentina dos Kirchners foram taxadas as exportações (e não a produção) de bens básicos. No segundo caso, o impacto no salário real da desvalorização é reduzido, pois o preço no mercado interno dos produtos exportados taxados cresce menos que a desvalorização.
} 
pode ser controlado tranquilamente comprando reservas (sem custo fiscal se o diferencial de juros for nulo). Esta é basicamente a estratégia seguida por uma série de países em desenvolvimento da crise asiática no final do século XX. No entanto, mantida a livre mobilidade de capitais de curto prazo, mudanças bruscas nos ciclos internacionais de crédito podem levar a fortes movimentos de saída pela conta de capitais, o que levaria ao retorno dos juros elevados para estancar a perda de reservas ou a ulteriores desvalorizações cambiais, que teriam impactos inflacionários. Assim, talvez fosse prudente, começar a se pensar em controle de capitais externos de curto prazo que, no mínimo, evitem a entrada indesejada de capital especulativo que tenha um potencial desestabilizador mais adiante. Já que conseguimos o "investment grade" não seria razoável ser mais seletivo em termos da qualidade do capital externo atraído?

Para concluir, gostaria apenas de lembrar que os difíceis dilemas entre inflação, taxa de câmbio e salários reais, típicos de uma economia em desenvolvimento, podem ser amenizados se houver uma grande expansão do investimento público em infraestrutura e tecnologia (muito superior ao modesto PAC), que melhore sistematicamente a produtividade, tanto dos setores industriais mais expostos à concorrência externa, quanto dos setores que produzem direta e indiretamente a cesta de bens e serviços relevante para os salários reais. Mas esta discussão nos levaria a analisar o outro pilar do regime de política macroeconômica vigente no Brasil, baseado na ideia de um ajuste fiscal permanente, cuja crítica fica para outra ocasião.

\section{REFERÊNCIAS BIBLIOGRÁFICAS}

BANCO CENTRAL (2008) “Taxa natural de desemprego no Brasil”. Relatório de Inflação. 2008 (Março) 129: 133.

BARBOSA-FILHO, Nelson (2007) "Inflation targeting in Brazil: 1999-2006". Disponível em www. networkideas.org.

BARBOSA-FILHO, Nelson (2008) Panorama da economia brasileira e estratégia da política econômica, série Seminários de Economia Brasileira em Perspectiva, FGV-SP, Março de 2008.

BRAGA, Julia M. (2006) "Raiz unitária, histerese e inércia: A controvérsia sobre a NAIRU na economia norte-americana nos anos 1990”. Tese não publicada.

BRESSER-PEREIRA, Luiz C. (2008) “The Dutch disease and its neutralization: a Ricardian approach" Revista de Economia Política, 28(1).

FERREIRA, Alexandre B. \& JAYME JÚNIOR, Frederico G. (2005) "Metas de inflação e vulnerabilidade externa no Brasil", Anais do XXXIII Encontro Nacional de Economia da ANPEC, 2005.

FREITAS, Alexandre L. (2006) "Uma interpretação heterodoxa para as relações de taxa de juros, câmbio e inflação no Brasil”. Dissertação de Mestrado não publicada, Instituto de Economia,UFRJ.

MAIA, André L. S. \& CRIBARI-NETO F. (2006) "Dinâmica inflacionária brasileira: resultados de auto-regressão quantílica”. Revista Brasileira de Economia, 60 (2): 153-165.

ROMER, David (2000) "Keynesian and macroeconomics without the LM curve". Journal of Economic Perspectives, vol. 14, n. 2 (Spring, 2000), pp. 149-169.

SERRANO, Franklin L. P. (2007) "Histéresis, dinâmica inflacionaria y el supermultiplicador sraffia- 
no”. Seminarios Sraffianos, UNLU-Grupo Luján. Colección Teoría Económica, Edicionones Cooperativas.

SUMMA, Ricardo F. (2007a) "Resposta a Schwartzman". Disponível em www. criticaeconomica.com.br. SUMMA, Ricardo F. (2007b) "Taxa de juros exógena no Brasil no período 2003-2007" Anais do II Coloquio de la Sociedad Latinoamericana de Economía Política v. II,Caracas.

VERNENGO, Matías (2008) "The political economy of monetary institutions in Brazil: The limits of the inflation-targeting strategy, 1999-2005”. Review of Political Economy, 20 (1): 95-110. 